\title{
7 \\ Navigation in Information Spaces: supporting the individual
}

David Benyon

\author{
Dept. Computer Studies \\ Napier University \\ 219, Colinton road \\ Edinburgh \\ EH14 1JD, UK \\ D.Benyon@dcs.napier.ac.uk
}

Kristina Höök

\author{
SICS (Swedish Institute of Computer \\ Science) \\ Box 1263 \\ S-164 28 Kista, Sweden \\ kia@sics.se
}

\begin{abstract}
The issue of how users can navigate their way through large information spaces is one that is crucial to the ever expanding and interlinking of computer systems. There are many ways of dealing with the issue of navigation. The use of appropriate metaphors is one, virtual reality and 3D interfaces another. A third is to provide adaptive interfaces based on individual differences in users navigational ability. This paper takes a critical look at the alternatives for assisting users to navigate information spaces and concludes by outlining a research agenda for navigation support.
\end{abstract}

KEYWORDS Navigation, Wayfinding, Information Space, Individual Differences

\section{INFORMATION SPACES}

The concept of an 'information space' is one that is becoming increasingly important in the current era of large and/or networked computers. Information spaces are manifested in such areas as multiple interacting databases where 'data mining' is a major issue, and in large hypermedia systems such as the World Wide Web (WWW). Traditional information retrieval systems can be seen as information spaces as can more everyday media such as a CD-ROM or a one or two gigabyte disc.

The concept of an information space is best understood by appealing to the notion of an information system, or information artifact. An information artifact is 'any artifact whose purpose is to allow information to be stored, retrieved, and possibly transformed' (Green and Benyon, 1996). Interactive devices such as spreadsheets, word processors, and music notations are clearly examples of information artifacts, but so are noninteractive devices like tables, documents and musical scores. An information artifact consists of two levels of description; a conceptual level provides some abstraction of the experienced world and a perceptual level provides a view, or viewport onto that structure. Thus a paper train timetable is one information artifact providing information about train journeys and a talking timetable is another (Bental, Benyon and Green, in press).

All information artifacts employ various symbols, structured in some fashion, and provide functions to manipulate the symbols (whether conceptually or physically). From these symbols people are able to derive information. Thus every information artifact defines an information space - the symbols, structure and functions which allows information to be stored, retrieved and transformed. 
As humans we live, work and relax in information spaces. At one level of description all our multifarious interactions with the experienced world are effected through the discovery, exchange, organisation and manipulation of information. Information spaces are not the province of computers. They are central to our everyday experience. Finding your way through an airport, a hotel or a city involves travelling in an information space. Paper documents represent another type of information space. Users will get quite different information from books, from newspapers and from magazines. Similarly they will find various information in timetables, guides and maps.

In computer systems there is a range of information spaces which demonstrate different characteristics. Cyberspace is 'a three-dimensional domain in which cybernetic feedback and control occur' (Walker, 1990). Navigation in such spaces is relatively unconstrained. Hyperspace, typified by hypertext or hypermedia systems, provides a structure in which the information nodes are linked and functions provided which facilitate following these links.

Large software systems such as spreadsheets and word processors are information spaces in which the user navigates by clicking on icons or selecting from menus. In contrast to these spaces which have been designed by system developers, physical media such as discs and CDROMs are information spaces which are primarily user structured. Users are responsible for deciding how to organise their information, how to name things, when to duplicate items and where to store them. Where networks of computers are involved issues such as authorisation and access become more important. On a single machine the user is rarely too worried about where he or she is in the system. In contrast location is a vital piece of information on a network.

Issues concerning the number of types of object and their attributes, the range of manipulative functions and the organisation and distribution of the information characterise different sorts of computer-based information space. It is also important to recognise that these spaces exist within time. A well-structured information space can soon become a tangled mess if someone or something is not there to organise it. Authorisations change, passwords expire and computers are replaced. Information space/time may be a better conceptualisation.

\section{MOVING AROUND IN INFORMATION SPACE}

Humans spend their lives in spaces; whether social, geographical, personal or informational, so it is not surprising that the nature of spaces and the ways in which we move around spaces has been studied from a number of perspectives. City planners (e.g. Lynch, 1977), geographers, anthropologists and historians deal with spaces, though from a social rather than psychological perspective. Architectural design (Passini, 1992) has considered issues of navigation in relation to the construction of buildings, shopping malls and theatres. Post-modern analysis of spaces takes a critical view of the 'traditional' psychological approach to space and navigation. (See Liggett and Parry, 1995 for a variety of perspectives on spatial theory and urban studies). It is perhaps surprising that these disciplines have commented so little on information spaces per se. For example, in his thorough account of spaces, Lefebvre (1991) identifies many different types of space: geographical spaces, ethnographical space, demographic space, musical spaces, plastic spaces and so on. However he comments 'we know enough...to suspect the existence of a space peculiar to information science, but not enough to describe that space, mush less to claim acquaintance with it' (p. 86). Shields (1991) is quick to dismiss the objectivist view of traditional geography, preferring instead a semiotic, culturallybased approach. The importance of socially-constructed ideas and values is indeed important, but by emphasising that people derive meaning from such interactions, he shifts us from a geographical to an informational space. The issue of how to travel in that space remains (O'Day and Jeffries, 1993; Shum, 1990).

Psychologists have tended to focus their attentions on the topic of moving around in information spaces; navigation. Neisser (1976) deals with navigation in terms of cognitive maps; the mental representations which people have of their environment. However, these are not static models. Ecological considerations are important as people draw important cues from the immediate environment and develop knowledge of the space over time and through the experience of interacting with it. Issues of navigation are central to Hutchins recent discussion of distributed cognition (Hutchins, 1995) and cultural differences have been explored with respect to navigation (Hutchins, 1983). A considerable amount has been published on Polynesian navigators in particular (see Hutchins, 1995 p 65 - 93). 
Much of the psychology of navigation is couched in terms of wayfinding. How do people work out how to reach their destination? The answers to this question are many and, often, unsurprising. People use maps and guides. They exploit landmarks in order to have something to aim for and to recognise a place when they arrive or use 'dead reckoning' at sea when there are no landmarks. Novel techniques can be provided to give the user different views of a real or virtual landscape fish-eye views focus attention on one area but provide a wide angle to overall view. Three dimensional 'fly overs' of virtual spaces are made possible with computer technology.

Learning to find ones way in a new space is another aspect of navigation considered by psychologists (Kuipers, 1982, Gärling et al. 1982). First, we learn a "linked-list-of-items" - when we see the hedge we know that we should turn left. Then we get to know some landmarks and can start relating our position with regards to this landmark. We learn the relative position of landmarks and start building mental "maps" of parts of the space in-between these landmarks. These maps are not complete but rather like pages in an atlas. Some of the pages are detailed others are not, and more importantly, the relation between the pages are not perfect. Some may be distorted with respect to oneanother. This process is fairly quick for a new city as shown by (Gärling et al. 1982). In a couple of weeks new students in a university city had formed their "atlas" over the city.

For the interests of developers of large scale computerbased information spaces, there may be much which can be learned from the psychological experiences of wayfinding in general. However, wayfinding is primarily concerned trying to reach a destination. Whilst trying to obtain some specific information is certainly one thing which users of computer systems do it is not the only thing. Users do not simply make plans and carry out appropriate actions. They browse, scan and wander through information space.

We might oppose the idea of wayfinding with the notion of exploration. With exploration, people are not trying to get anywhere, they are not trying to find their way. Instead they are just interested to have a look around. On many occasions they will not want to return to this particular space. Exploration is concerned with finding out about a local environment and perhaps how that environment relates to other environments. The user is interested in the nature of the terrain, with seeing new vistas. The recognition of place can be important, but much knowledge in exploration is knowledge in the world, and need not be made knowledge in the explorer's head.

A third activity which is undertaken in information space is identifying objects. Here the user is less interested in the location of objects, nor is the user interested in finding a path or reaching a goal. Although object identification is somewhat akin to exploration, the purpose of the activity is different. Exploration focuses on understand what exists in an environment and how the things are related. Object identification is concerned with finding categories and clusters of objects spread across environments, with finding interesting configurations of objects and finding out information about the objects.

\section{INDIVIDUALS IN INFORMATION SPACES}

One of the main problems with systems design is dealing with individuals. In the information spaces which we provide, we need to cater for users who have very different goals from other users. We need to accommodate users who have ill-formed goals, different experiences and different domain knowledge.

Users have different capabilities, preferences and different skills. There is now enough knowledge of individual differences and navigation to say that these differences are important and significant. In some experimental work (Benyon and Murray, 1993), found a clear influence of spatial ability on navigation in a database. Subjects used a command interface to a database system and were measured on experience of using command interfaces and spatial ability. The results showed that many limitations on subjects' performance on the command interface, which related to their spatial ability, could be overcome with experience. However, a scatter plot of subjects' spatial ability scores against their test session times shows clearly that not all the limitations of low spatial ability are overcome by high experience (Figure 1).

Vicente and colleagues (1987) also found that spatial ability affected users ability to navigate a large file structure. More recently Höök and her colleagues have found a similar result (Dahlbäck, et al., 1996). This study is particularly interesting as the researchers have tried to tease apart the nature of the cognitive ability which affects navigation in information as opposed to geographic space. The experiment demanded that users undertake real navigation problems in a hypermedia system. The strongest result showed a correlation (with a chance probability less than .005) between users abilities on tests involving the mental rotation of 
images and their task completion time (see Figure 2). Overall the distribution is similar distribution to that shown in Figure 1. The differences between the individuals overall shows just how important individual differences are in navigating information spaces. The fastest subject solved the tasks 19 times faster than the slowest

The tests of spatial ability used in the study by Dahlbäck et al (1996) showed that the tests which allowed subjects to rotate or manipulate blocks or draw figures did not correlate with navigation in hypermedia, but instead correlated with the subjects subjective estimating of their map-reading ability. The researchers conclude that there is a difference between spatial ability for solving problems in the world and the spatial ability for solving problems in the abstract world of information spacesubject.

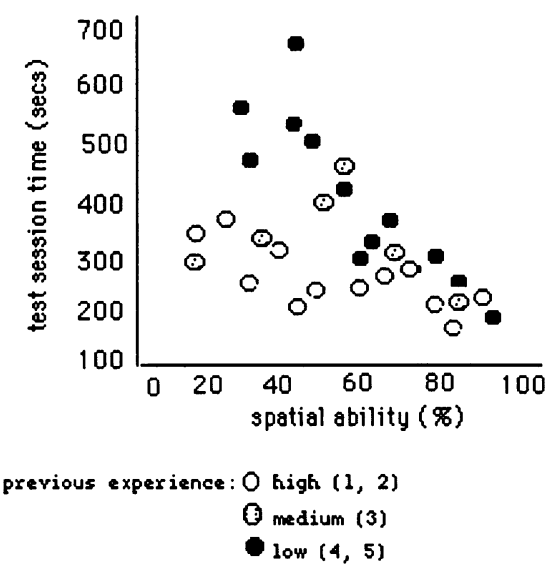

Figure 1 Subjects' test session times against their spatial ability scores, giving their command experience.

The fact that individual differences do have an impact on navigation seems incontrovertible. The spatial ability to rotate objects is certainly one factor which has been found to influence people's abilities to navigate. Experience is another, technical aptitude another (Borgman, 1989) and learning style appears to be another (Esichaikul et al., 1994). We also know that some individuals like using maps and others do not, preferring verbal instructions over graphical representations (Streeter et al., 1985, Streeter and Vitello, 1986) There are important novice vs. expert differences as demonstrated by studies of taxi drivers (Pailhous, 1970, Chase, 1983).

\section{METAPHORS FOR INFORMATION SPACES}

One solution which designers have is to exploit a metaphor in the design of their navigational aids. Vicente and Williges (1988) found that by introducing a visual, concrete metaphor, they were able to assist users in navigating their file system. However, metaphor needs using with care if it is to deal with the range of activities which users are engaged in, the nature of the information space and differences between individuals.

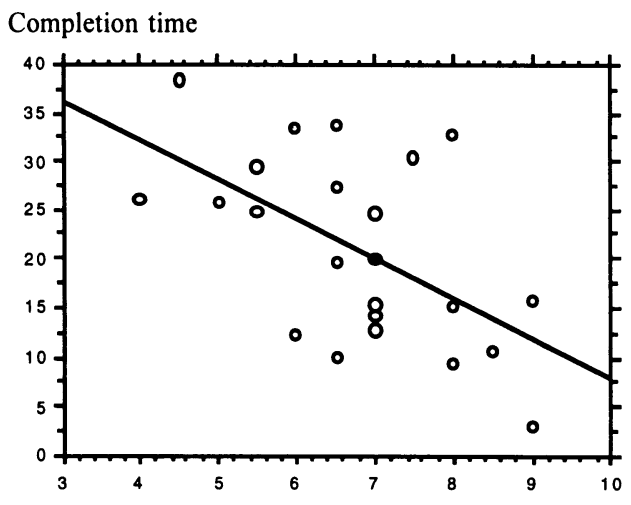

Spatial ability (measured in stanine points)

Figure 2. The correlation between completion time and spatial ability.

Alan Kay has criticised the use of metaphor as a design approach because the computer allows us to escape from the limitations of erstwhile devices and we do not want to import the restrictions inherent in a metaphor into novel systems (Kay, 1990). However the use of extended and complex metaphors continues to be popular with designers and there have been many examples of designers employing rich metaphors in their systems. For example, Card's Rooms metaphor (Card, et al., 1991), the Information City (Dieberger, 1994), Guides (Oren, et al., 1990) and so on. General advice on selecting a metaphor (such as considering the nature of the user population and the correspondence between the structure and functioning of the metaphor and the underlying system) has been published (e.g. Erickson, 1990; Carroll et al., 1988), but little has been said about metaphor and navigation in general. As we 
have seen, users will want to do different things in the information spaces, and metaphors will help or hinder them in those activities. The different types of information space will demand different types of metaphor.

One recent conference on spatial metaphors and hypertext (Dieberger, 1994) offers some useful ideas. For example, Benking and Judge (1994) identify types of metaphor: 'geometric forms (cube, sphere, polyhedra in general), artificial forms (townscapes, house, room), natural forms (landscape, trees, etc.), systemic structures (highway systems, pathways, flow systems), dynamic systems (atomic, molecular, planetary, galactic systems), traditional symbol systems (mandalas, sand paintings, etc.)'. Besides these overall metaphors, 3D style interfaces can be effective in helping users to visualise the information space, providing a simulated 'fly-over' effect. Given the right software (such as Hyper-G and the Harmony browser), the visualisation can be generated automatically with the attributes of the information objects being used to structure the display (Maurer, 1996 gives a full description of the Hyper-G server and its browsers).

Spatial metaphors come in a wide variety of forms. A city metaphor is one popular example. A city metaphor employs the familiar constructs of roads, subways, houses, shops and a variety of buildings. For example, Dieberger (1994) states 'We are used to navigate cities using very vague descriptions and using various navigational tools like maps, verbal descriptions, sketches, navigational infrastructure (signposts), personal inquiry, transport systems (taxis, subways) and collaboration. Cities are large structured spaces and they can easily be connected to systems containing several cities by using some simple transport systems between cities. Cities are dynamic spaces and people cope well with limited change in those spaces whereas they get quite confused when there is some change in the spatial structure of - say - a desktop. There is a rich body of knowledge about the organization of cities and navigation in cities that can provide a starting point how to make the city metaphor usable as organising principle in a virtual world.' He also points out that users can be transported quickly 'by magic' from one part of the city to another without feeling disorientated as the concept maps well onto using the subway (which counters some of Kay's criticism). There is no doubt that cities provide a rich metaphor, suitable for exploring and locating specific objects.

Other metaphors which might be useful for thinking about navigation include a wilderness (frightening, confusing, enchanting) or a desert (intimidating, beautiful, with no landmarks). Such metaphors might encourage forging a path, enjoying the scenery and getting out. Wilderness and desert can be included in an overall countryside metaphor where different types of terrain represent different types of information. These metaphors encourage exploration by the user; the system provides a high level metaphor, but the user provides a more detailed structure

The night sky offers a different sort of space. It represents objects, clusters, patterns and it is very big. It supports the activities of mapping and identifying objects. However, there are relatively few types of object in the night sky (galaxies, stars, planets). It is the configurations and sub-types of these objects which is of interest. Science fiction concepts such as warp drives and worm holes can be sued for quick and magic transportation to distant parts of the space.

The open sea is another metaphor. It encourages a distinction between the surface and depth. Thus it is natural to think of a lot of information as being hidden beneath the surface and only available for viewing if the user dives down. Currents can link continents and islands and take people to unexpected places. People can look for islands of information; archipelagos provide clusters. Waterworth (1996) combines an island metaphor with a personal 'vehicle' space.

A $3 \mathrm{D}$ or $4 \mathrm{D}$ object offers a different perspective. Here the user can see the whole of the space and can manipulate it, rotate it. It is suited to users who want to see the whole space and become orientated. A museum has been structured to allow free roaming, yet is also structured to facilitate learning. A library is suitable for finding information. It is well-organised and structured. The librarian has already organised the material with like subjects kept together. A breakfast bar (so popular in holiday hotels) offers another type of metaphor. Here a whole range of choices are laid out for the users. The user can see how far the space extends and can be offered choice. Users are encouraged to feed a need, to take what they want and to come back for more. It's a constrained, help yourself environment.

This is not intended to be an exhaustive list, nor even to provide an example of each possible type of metaphor. Metaphors work by providing correspondences between one domain and another (Lakoff, 1988). In using them as the basis of a physical design, it is important that these correspondences are consistent and meet with users expectations. Moreover, it is important that the metaphors support what users want to do in that space - to find a way, to identify, 
cluster and classify, or simply to wander around and explore.

\section{A WAY FORWARD FOR NAVIGATION SUPPORT}

We live in a world of information spaces. Increasingly these are very large computer-based information spaces. Whether the information space is an application, a hard disc, a CD-ROM, a local area network or the Internet, the problem of how to help the user to navigate, explore and identify the objects of interest is critical to the success of the system.

There is much that computer system designers can learn from other disciplines which deal with space. Lynch (1977) identifies techniques based on a number of characteristics such as; spatial form (different types of models, maps, etc.), temporal form (showing the history of development), sequencing to show paths through a space, visibility to show alternative vistas and ambient qualities of different parts of the space. Architecture (Passini, 1992) provides another perspective. However, we have, in addition, our own problems and our own opportunities.

The abstract nature of information space means that designers have to import the concrete from elsewhere. Metaphors for conceptualising information space can exploit common well-grounded experience from the users world. But care needs to be taken to provide consistency and completeness. We must be wary about importing from the concrete world to the abstract informational world what we think aids navigation. We must also be aware that it is important not simply to wander around an information space. Users usually want to obtain and remember some information and solutions which hide too much may aid navigation at the expense of reducing the amount of information obtained. Metaphors must also be chosen which allow the users to find their way, to wander, scan the space and identify what they want. Information spaces also make different demands on different users owing to their different cognitive capabilities - in particular some measure of their spatial ability.

Computer-based information spaces, however, have a great opportunity. They do not have to be single, stable spaces; they can be adaptive. In a review of adaptive hypermedia systems, (Brusilovsky, 1996) identifies the following types of navigational support which may benefit from some adaptiveness. Direct guidance systems decide which is the next most appropriate node for users. Adaptive ordering adjusts the order of links on a page - for example by making more relevant links nearer to the top of a display. Hiding constrains the size of the information space by automatically hiding pages from users and adaptive annotation adds additional information to links in the form of textual annotation, icons, colour and so on. To be effective these adaptations need knowledge of the individual user; the cognitive characteristics, purpose and domain knowledge which the individual has. Maes (1994) has shown that relevant knowledge about user preferences can be quickly inferred from their early choices and (Benyon and Murray, 1993) show how cognitive characteristics can be inferred from error rate.

Although we have a good understanding of the factors which affect navigation and we have a range of possible design solutions to these problems, the research has yet to demonstrate which problems can be solved by which solutions. For example, adaptive hypermedia systems that hide parts of the nodes can be used to reduce the information space. However, a low-spatial user may still have problems - not with the overview of the space, perhaps but with local decisions such as where to go next. If the adaptive system proposes where to go next it won't necessarily prevent the user from feeling lost.

Adaptive annotations and adaptive interfaces (for example changing a graphical map into a verbal set of instructions) can be of use if carefully designed and matched with individuals differences which have a real impact on the usability of the system. Appropriate metaphors and visualisations of the information space can aid object identification and object clustering.

A radical alternative to these approaches is to base navigation on a socially-based, rather than geographically-based footing. "Social navigation" could be one way forward to help users who cannot be helped by maps. Such users might prefer to converse with interface agents, to discuss their information needs rather than having to find their own way to the information. This notion can be extended to filtering agents (Maes, 1994) which organise and structure information, leaving the user to evaluate the relevance of the contents.

The use of narrative offers another solution as suggested by Laurel and others (Laurel, 1991). Through a mixture of stereotypical narratives learnt by everybody and ways of moving between scenes and lines of actions, film or theatre can seduce us to think that we know how to orient ourselves and also to look in certain directions for interesting things.

We see the issue of navigation in information space as one of the most important in interactive system design. From our research we can confidently predict that if 
designers create large information spaces without paying careful attention to navigational aids, then there will be significant differences in performance between individuals. These differences will include the time they take to retrieve information, the confidence which they have in the results which they obtain, their satisfaction in using the system and in their ability to learn the system. In short, the usability of the system will be radically different for different users.

To combat this lack of usability, we propose that designers should look at the use of metaphor, at employing adaptive techniques and at utilising social approaches to supporting navigation. We must also look at the experiences of navigational support provided by both the geographical view of space, by social alternatives to this view and by semiotic approaches (Gottdiener and Lagopoulos, 1986).

We as designers are involved in the production of information space. However, users of the space are equally involved in its production. It is they who attach meaning to the space. It is they who have to live in the space.

\section{REFERENCES}

Benking, H. and Judge, A. J. N. (1994) Design Considerations for Spatial Metaphors. Presentation at ECHT'94 - the European Conference on Hypermedia technology, Sept. 1994, Edinburgh. Available from http://www.lcc.gatech.edu/faculty/Dieberger/ECHT94. WS.toc.html

Bental, D. Benyon D. R. and Green, T. R. G. (in press) Understanding and Building Entity-relationship Models of Information Artifacts.

Benyon, D. R. and Murray, D. M. (1993) Adaptive Systems; from intelligent tutoring to autonomous agents. Knowledge-based Systems, 6 (3)

Borgman, C. L. (1989) All Users of Information Retrieval Systems are not Created Equal: an exploration into individual differences, Information processing and management vol. 25, no. 3, pp. 237251.

Brusilovsky, P. (1996) Adaptive Hypermedia: An Attempt to Analyse and Generalise. In Brusilovsky, P., Kommers, P. and Streitz, N. (eds.) Multimedia, Hypermedia and Virtual Reality LNCS 1077 Springer Verlag

Card, S. K., Robertson, G. C. and Mackinlay, J. D. (1991) The Information Visualizer, an Information Workspace. In Proceedings of CHI '91 Conference on Human factors in Computing Systems, ACM publications, New York pp 181 - 188.
Carroll J.M., Mack R.L., and Kellogg W.A. (1988) Interface Metaphors and User Interface Design, in Helander M. (Ed.): Handbook of Human-Computer Interaction, Elsevier pp. 67-85

Chase, W.G. (1983) Spatial Representations of Taxi Drivers, In D. R. Rogers and J.A. Sloboda (eds.) Acquisition of Symbolic Skills, pp. 391-405, New York Plenum.

Dahlbäck, N., Höök, K., and Sjölinder, M. (1996) Spatial Cognition in the Mind and in the World - the case of hypermedia navigation, The Eighteenth Annual Meeting of the Cognitive Science Society, University of California, San Diego, July, 1996.

Dieberger, A. (1994) Spatial environments to organize and navigate information and to communicate about this organization, Presentation at ECHT'94 - the European Conference on Hypermedia technology, Sept. 1994, Edinburgh. Available from http:// www.lcc.gatech.edu/faulty/Dieberger/ECHT94.WS.toc .html

Erickson, T. D. (1990) Working with Interface metaphors. In Laurel, B. (ed.) The Art of HumanComputer Interface Design Addison-Wesley, Cambridge, Ma.

Esichaikul, V., Smith,, R. D. and Madely, G. R. (1994) The impact of learning style on problemsolving performance in a hypertext environment Hypermedia 6 (2) 101 - 111

Gottdiener, M. and Lagopoulos, A. (1986) (eds.) The City and the Sign Columbia University Press, New York

Green, T. R. G. and Benyon, D. R. (1996) The skull beneath the skin; Entity-relationship modelling of Information Artefacts. International Journal of Human-Computer Studies 44(6) 801-828.

Gärling, T., Böök, A., and Ergesen, N. (1982) Memory for the Spatial Layout of the Evryday Physical Environment: Different Rates of Acquisition of Different Types of Information, Scandinavian Journal of Psychology, 23, pp. 23-35.

Hutchins, E. (1983) Understanding Micronesian Navigation. In Gentner, D. and Stevens, A. L. (eds) Mental Models. Erlbaum

Hutchins, E. (1995) Cognition in the Wild MIT press, Cambridge Ma.

Kay, A. (1990) User Interface: A Personal View. In Laurel, B. (ed.) The Art of Human-Computer Interface Design Addison-Wesley, Cambridge, Ma.

Kuipers, B. (1982) The 'Map in the Head' Metaphor, Environment and Behaviour, 14, pp. 202-220. 
Lakoff, G. (1988) Cognitive Semantics. In Eco, U., Santambrogio, M. \& Violi, P. (eds.). Meaning and Mental Representations. Indiana University Press.

Laurel, B. (1991) Computers as Theatre, AddisonWesley Publ. Comp.

Lefebvre, H. (1991) The Production of Space Blackwell, Oxford

Liggett, H. and Parry, D. C. (eds.) (1995) Spatial Practices SAGE publications Thousand Oaks, Ca.

Lynch K (1977) Managing the sense of a Region MIT press, Cambridge, $\mathrm{Ma}$.

Maes P. (1994) Learning Agents in Communications of the $A C M$. August

Maurer, H. (1996) HyperWave. The next generation web solution Addison-Wesley Longman, Harlow, UK

Neisser U. (1976) Cognition and Reality W. H. Freeman and Company, San Francisco.

O'Day, V. and Jeffries, R. (1993) Orienteering in an Information Landscape: How Information Seekers Get from Here to There, Proc. ACM InterCHI'93, pp. 438445.

Oren, T. Salomon, G., Kreitman, K. and Don, A. (1990) Guides: Characterising the Interface. In Laurel, B. (ed.) The Art of Human-Computer Interface Design Addison-Wesley, Cambridge, Ma.

Pailhous, J. (1970) La Représentation de l'Espace

Urbain, Paris: Presses Universitaires de France.

Passini, R. (1992) Wayfinding in Architecture Van Nostrand Reinhold

Shields, R. (1991) Places on the Margin Routledge, London, UK

Shum S.B. (1990) Real and Virtual Spaces: Mapping from spatial cognition to Hypertext, Hypermedia, Vol .2, No.2 pp. 133-158

Streeter, L., Vitello D., and Wonsiewicz, S. (1985) How to Tell People Where to Go: Comparing Navigational Aids, International Journal of ManMachine Studies, 22, pp. 549-562.

Streeter, L. and Vitello, D. (1986) A Profile of Drivers' Map-Reading Abilities, Human Factors, 28(2).

Vicente, K.J., Hayes, B.C., and Williges, R.C. (1987) Assaying and Isolating Individual Differences in Searching a Hierarchical File System, Human Factors, 29(3), pp. 349-359.

Vicente, K.J., and Williges, R.C. (1988) Accomodating Individual Differences in Searching a Hierarchical Fiel System, International Journal of Man-Machine Studies, 29, pp. 647-668.

Vicente, K. and Williges, R.C., (1988) Visual Momentum as a means of accommodating individual differences among users of a hierarchical file system.
In: J. Rasmussen and P. Zunde (Eds.), Proc. 5th Symposium EFISS, Risø National Laboratory, Denmark, November 1987 (New York: Plenum Publishing).

Walker, J. (1990) Through the Looking Glass In Laurel, B. (ed.) The Art of Human-Computer Interface Design Addison-Wesley, Cambridge, Ma.

Waterworth, J., (1996). A Pattern of Islands: Exploring Public information Space in a Private Vehicle. In Brusilovsky, P., Kommers, P. and Streitz, N. (eds.) Multimedia, Hypermedia and Virtual Reality LNCS 1077 Springer Verlag. 